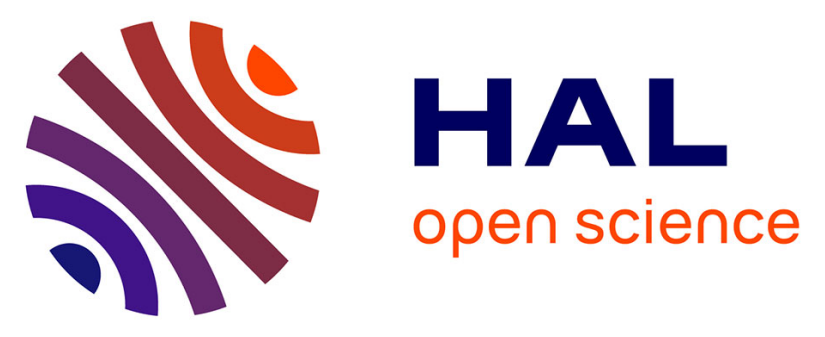

\title{
In situ measurements of the structure and strain of a $\pi$-conjugated semiconducting polymer under mechanical load
}

\author{
Mouaad Yassine Aliouat, Stephanie Escoubas, Mohamed Chérif Benoudia, \\ Dmitriy Ksenzov, David Duché, Evangéline Bènevent, Christine \\ Videlot-Ackermann, Jörg Ackermann, Olivier Thomas, Souren Grigorian
}

\section{To cite this version:}

Mouaad Yassine Aliouat, Stephanie Escoubas, Mohamed Chérif Benoudia, Dmitriy Ksenzov, David Duché, et al.. In situ measurements of the structure and strain of a $\pi$-conjugated semiconducting polymer under mechanical load. Journal of Applied Physics, 2020, 127 (4), pp.045108. 10.1063/1.5127226 . hal-02495485

\section{HAL Id: hal-02495485 \\ https://hal.science/hal-02495485}

Submitted on 2 Mar 2020

HAL is a multi-disciplinary open access archive for the deposit and dissemination of scientific research documents, whether they are published or not. The documents may come from teaching and research institutions in France or abroad, or from public or private research centers.
L'archive ouverte pluridisciplinaire HAL, est destinée au dépôt et à la diffusion de documents scientifiques de niveau recherche, publiés ou non, émanant des établissements d'enseignement et de recherche français ou étrangers, des laboratoires publics ou privés. 


\title{
In-situ measurements of the structure and strain of a
}

\section{$\pi$-conjugated semi-conducting polymer under}

\author{
mechanical load.
}

\author{
Mouaad Yassine Aliouat ${ }^{1,2}$, Stéphanie Escoubas ${ }^{1}$, Mohamed Chérif Benoudia ${ }^{2}$, \\ Dmitry Ksenzov ${ }^{3}$, David Duché2, Evengeline Bènevent ${ }^{1}$, Christine Videlot-Ackermann ${ }^{4}$, \\ Jorg Ackermann ${ }^{4}$, Olivier Thomas ${ }^{1}$ and Souren Grigorian ${ }^{3}$ \\ ${ }^{1}$ Aix Marseille Univ, Université de Toulon, CNRS, IM2NP, Campus de St-Jérôme, 13397, \\ Marseille, France \\ ${ }^{2}$ Ecole Nationale Supérieure des Mines et de la Métallurgie, L3M, W129 Annaba, Algeria \\ ${ }^{3}$ Institute of Physics, University of Siegen, Walter-Flex-Strasse 3, D-57068 Siegen, Germany \\ ${ }^{4}$ Aix Marseille Université, CNRS, CINaM UMR 7325, Campus de Luminy, 13288, Marseille, \\ France
}

Keywords: GIXD, structure, strain, conjugated polymers, in-situ mechanical testing, flexible organic films. 
In this work, in-situ studies of organic thin films under stretching are developed. A high efficiency PffBT4T-2OD $\pi$-conjugated polymer (PCE11) was coated directly on a stretchable substrate in order to examine the impact of tensile strains on the structural properties. For that purpose, in-situ grazing incidence X-ray diffraction (GIXD) coupled with optical microscopic observations have been carried out to measure the structural parameters of PCE11 and to probe the mechanical behavior of polymer chains under uniaxial tensile load. It is observed that in the range between 0 and $15 \%-20 \%$ of stretching, the polymer chains become more oriented. Meanwhile an increase of negative values of deformation i.e. compression of the polymer chains along the film normal was measured. Beyond this range of stretching, the polymer order declined and the stress was relaxed. This relaxation is explained by the increased number of cracks spreading over the entire film as observed by optical microscopy.

\section{Introduction}

The development of polymer-based devices has shown tremendous progress in term of flexibility as well as stretchability, whether in OLEDs, ${ }^{[1,2]}$ OFETs, ${ }^{[3,4]}$ or OPV ${ }^{[5,6,7]}$ It opens extremely promising opportunities and wide research area for innovative and cheap devices. ${ }^{[8]}$ The $\pi$-conjugated semiconducting polymers and oligomers are the main elements that compose these devices owing to their optical and semiconductor properties. ${ }^{[9]}$ For photovoltaic applications, the active donor materials must present two basic structural features: ${ }^{[10]}$ First, a $\pi$ conjugated backbone composed of a repetition of units resulting in an extended $\pi$ orbital along the polymer chains, which allows charge transport and optical absorption; ${ }^{[11,12,13]}$ secondly alkyl side chains that represent the functionalization of the polymer core with solubilizing substituents, which is essential for inexpensive manufacturing by solution methods, as well as to enhance 
solid state core interactions. ${ }^{[14,15]}$ This renders the polymer soluble in organic solvents such as chlorobenzene $(\mathrm{CB})$, dichlorobenzene and chloroform.

Moreover, the use of flexible or even stretchable supports, such as poly(dimethylsiloxane) (PDMS), ${ }^{[16]}$ is paving the way to the emergence of the fields of flexible and stretchable electronics and photovoltaic devices, ${ }^{[6,7]}$ which opens many new applications in the fields of entertainment or health thanks to their stretchability ${ }^{[16,17]}$ and biocompatibility, ${ }^{[18,19]}$ and studies such as probing lifetime against mechanical load. ${ }^{[20]}$ Despite the progress in this field, there is still a lack of understanding of the behavior of the structure and optoelectronic properties of the organic materials under mechanical load.

There are only few reports and studies concerning the mechanical behavior and the change of photovoltaic parameters under mechanical tests. ${ }^{[6,7,21,22,23]}$ In these studies, stretching and transferring process were used to probe the structural and photovoltaic properties and to follow the adhesion of layers using optical microscopy ${ }^{[22]}$ and pre-strained PDMS. ${ }^{[6]}$ Only a very little change in photovoltaic properties was reported under high stretching (100\% of stretch) ${ }^{[22]}$

However, the stretching and transferring process ${ }^{[22]}$ can generate a compression strain during the transfer by stamping. To avoid the impact of layer transferring on the structure, the polymer thin film has been spin-coated directly on the PDMS. Improvement of coating on such stretchable supports will then make it possible to perform in-situ grazing incidence X-ray diffraction (GIXD) measurements during stretching. GIXD allows probing the structural properties of the crystalline part of the polymer layers. These semi-crystalline polymers are weak-scattering materials and their structural features are mainly accessible at the synchrotron radiation sources. Previously in-situ GIXD technique was successfully realized for the real-time studies of the formation of the conjugated polymer ${ }^{[24]}$ and oligomer ${ }^{[25,26]}$ films. 
In this manuscript, we present a methodology for in-situ probing of the structural and morphological changes of thin films of Poly[(5,6-difluoro-2,1,3-benzothiadiazol-4,7-diyl)-alt(3,3'"'-di(2-octyldodecyl)-2,2',5',2',5',2,"'-quaterthiophen-5,5',-diyl)] (PffBT4T-2OD), called also PCE11, under stretching. PCE11 is one of the most promising donor polymers with high power conversion efficiency in blend with $\mathrm{PC}_{71} \mathrm{BM}$, and it presents also a relatively good crystallinity. ${ }^{[27,28,29]}$ Despite mentioned progress, there have been many controversial discussions about the relationship between charge transport and structural order in conjugated polymers, ${ }^{[30,31]}$ and also in-situ studies to probe the structure and charge mobility upon thermal treatments, ${ }^{[32]}$ to improve efficiency, ${ }^{[33]}$ or prolonging the lifetime. ${ }^{[34]}$ In this work we studied the structural properties of the donor semi-crystalline polymer (PCE11) film, i.e. the changes in the scattered intensity, inter-planar distances, and re-orientations under tensile strain are measured by in-situ GIXD using a custom-made stretching device, whereas their morphology is studied employing in-situ microscopic optical observations of the surface.

\section{Methods}

\subsection{Substrates and film preparation}

The structure of PCE11 exhibits a $\pi$-conjugated backbone and the alkyl side chains (the chemical structure is shown in figure 1.a.).

The PCE11 powder was purchased from 1-Material Inc, with a purity of $99.99 \%$ (major impurities are trace metals), a molecular weight $\mathrm{Mw} 80 \mathrm{KD}$, and polydispersity of 2-2.5. The PCE11 was dissolved in CB with a concentration of $15 \mathrm{mg} / \mathrm{ml}$, stirred at $110^{\circ} \mathrm{C}$ more than 1 hour into a glove box with a low oxygen concentration of $200 \mathrm{ppm}$. The first step in the substrate preparation consists of cleaning and degreasing the surface using acetone, ethanol, and water in 
an ultrasonic bath during 15 min for each bath, followed by drying using argon flux gas. The surface was activated using UV-ozone treatment for $10 \mathrm{~min}$ at $80^{\circ} \mathrm{C}$ to improve the wettability on the stretchable substrate. ${ }^{[35,36]}$
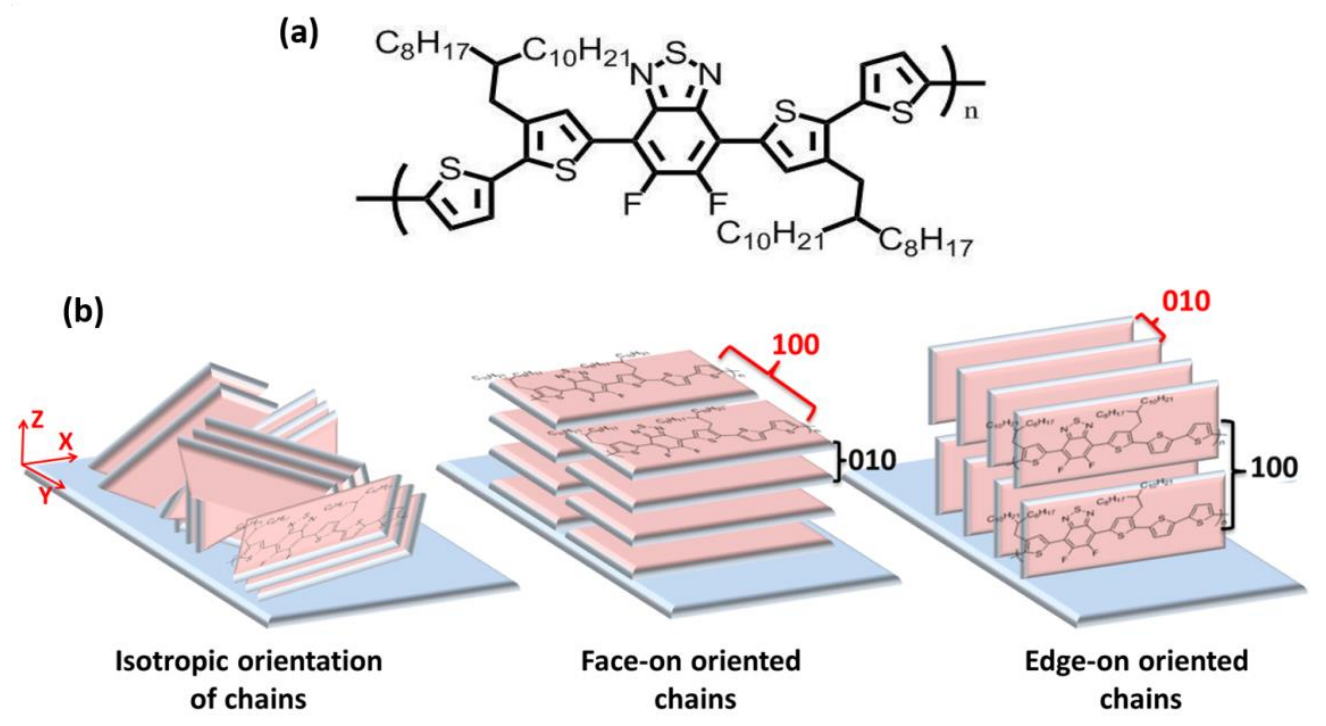

Figure 1. (a) PCE11 chemical structure, (b) Schematic representation of different crystalline packings of $\pi$-conjugated polymers

The PCE11 ink was spin-coated both on glass (as a reference) and on the stretchable substrate. We chose PDMS as stretchable substrate, which is a well suitable support with good mechanical properties (stretching up to 100\%) and transparent for PV applications. PDMS was obtained by spin coating with a $500 \mathrm{rpm}$ during $11 \mathrm{~s}$ using a 184 Silicone Elastomer from Dow Corning on a Kapton support, and then it was annealed at $100^{\circ} \mathrm{C}$ during 35 min. The achieved PDMS thickness is $400 \mu \mathrm{m}$, measured with a mechanical Brucker Dektak profilometer.

After activation of the substrate surface, we spin-coated the PCE11 ink at $1000 \mathrm{rpm}$ for $1 \mathrm{~min}$ on the glass and also directly on the PDMS substrate heated at $110^{\circ} \mathrm{C}$. During the spin-coating, the PDMS substrate was placed on a rigid glass support to improve the homogeneity of the layer. 
The size of each PDMS substrate is $36 \mathrm{~cm} \times 16 \mathrm{~cm}$, and the spin-coating was performed in the central area of the PDMS, on a surface of around $16 \times 16 \mathrm{~cm}^{2}$.

We fabricated many samples in order to optimize the PDMS surface treatment and to perform test stretching experiments in the lab. Among them, the 4 most homogeneous were chosen for insitu measurements (while stretching) during a synchrotron beamtime.

\subsection{Experimental setup}

We performed in-situ GIXD measurements at beamline BL9 of DELTA synchrotron radiation facility at TU Dortmund, Germany. The photon energy was $15 \mathrm{keV}$, corresponding to a wavelength of $0.83 \AA$. We used a wide area image plate 2D MAR3450 detector $(3450$ x 3450 pixels, with resolution of $100 \mu \mathrm{m} /$ pixel). The distance between the sample and the detector was $347 \mathrm{~mm}$, and the calibration was done by measuring the diffraction pattern of a silicon powder. This distance was chosen to be in the range of scattering vector $q$ from 0 to $2 \AA^{-1}$. A photodiode point detector was used for aligning the sample surface. The incidence angle $\left(\alpha_{i}\right)$ was chosen at $0.1^{\circ}$ to be slightly above the critical angle of total reflection of the film, and also to be more sensitive to the structure of the whole polymer thin film.

The exposure time was $5 \mathrm{~min}$ for each measurement, still avoiding beam damage because the brilliance of this synchrotron is low as compared to other synchrotrons. Indeed, we have tested the beam damage on PCE11 during $1 \mathrm{~h}$ exposure time, and we did not see any evolution of the diffraction pattern of the polymer. 


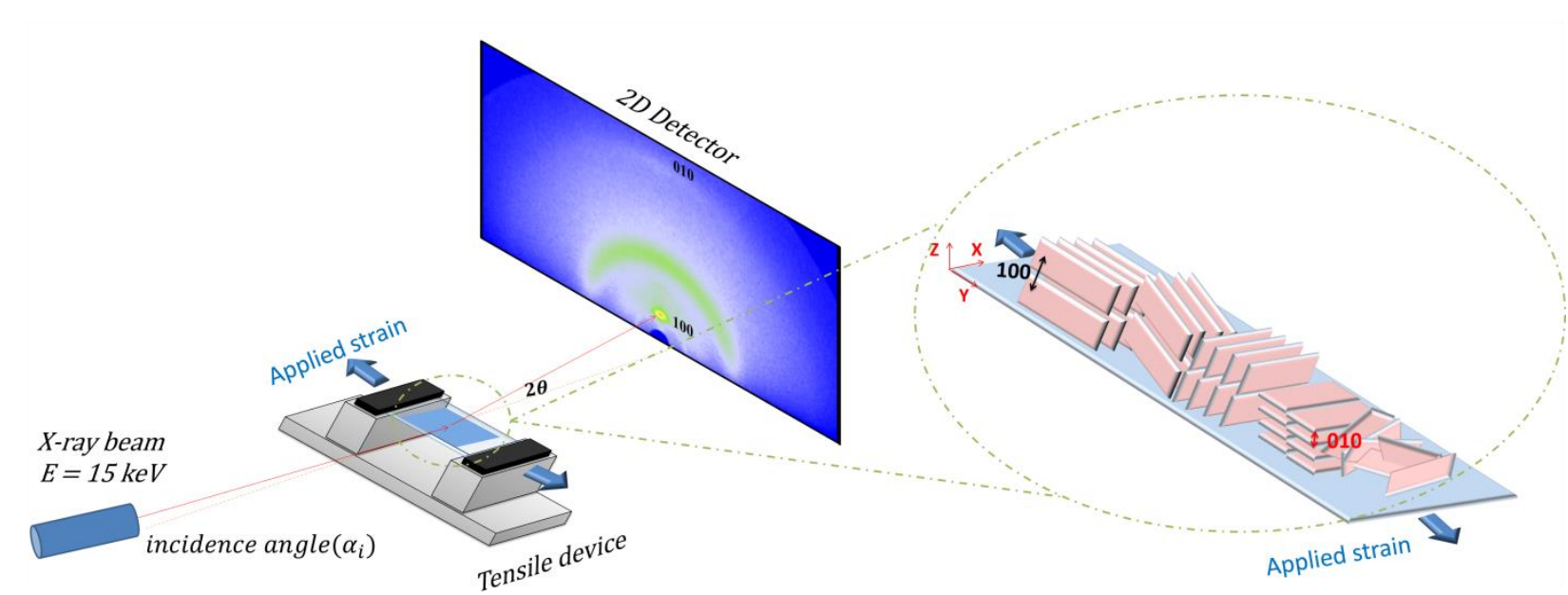

Figure 2. Schematic view of $i$-situ stretching GIXD experimental setup

In-situ GIXD measurements under stretching were carried out by using a specially designed tensile device with controlled load and two moving jaws (where high uniaxial loading can be achieved). The schematic representation of in-situ stretching GIXD setup is shown in figure 2. The X-ray beam was perpendicular to the stretching direction, and after each stretching step, we performed surface alignment to ensure that the measurement was done in the same region during all the experiment.

In-situ optical microscopic observations were performed during stretching to probe the microstructure of the layers, by using an OLYMPUS DP71 optical microscope with a magnification of 11.5. This optical microscope was fixed on the stretching machine in a way to observe the same area on the sample surface.

\section{Results and Discussion}

\subsection{Polymer film orientations}


The structure of $\pi$-conjugated semiconducting polymers is semi-crystalline with polymer chains orientation either isotropic, or exhibiting a preferential orientation like edge-on or face-on (figure 1.b). In face-on orientation, the interchain distance is parallel to the substrate surface, whereas in edge-on orientation this distance is perpendicular to the surface.

GIXD measurements allow determining the orientation and the different distances between polymer chains. These distances correspond either to a lamellar stacking that gives rise to h00 peaks or to the aromatic $\pi$ - $\pi$ stacking that gives rise to $0 \mathrm{k} 0$ peaks. By red and black colors in figure 1.b we schematically indicate the inter-planar distance which contributes to diffraction peaks along the in-plane and out-of-plane directions, respectively.

\subsection{From rigid to stretchable substrate}

The 2D GIXD patterns of PCE11 spin-coated on glass and on PDMS substrates are represented in figure 3.a and 3.b, respectively. Both patterns show the strongest scattered intensity along the vertical $\left(\mathrm{q}_{\mathrm{z}}\right)$ axis which corresponds to out-of-plane direction. The pattern in figure 3.a reveals a highly edge-on oriented PCE11 film coated on glass, with the strongest h00 peak being detectable until the fourth order along the out of plane direction $\left(\mathrm{q}_{\mathrm{z}}\right)$. The aromatic $\pi$ $\pi$ stacking ring along both the out-of-plane $\left(\mathrm{q}_{\mathrm{z}}\right)$ and the in-plane $\left(\mathrm{q}_{\mathrm{x}}\right)$ directions are also visible (010 peak). On the other hand, the pattern of PCE11 coated on PDMS (figure 3.b) reveals a less edge-on oriented film, with the 100 peak only visible until the second order along $\mathrm{q}_{\mathrm{z}}$ and a weak peak along $\left(\mathrm{q}_{\mathrm{x}}\right)$, together with a pronounced contribution of the amorphous PDMS ring.

In order to quantify the orientation of polymer chains and to probe the anisotropy, we performed an azimuthal integration of the patterns by an arc-cut to the 100 peak, characterized by its radius, width, center and its angular range (see figure S1.a in Supplementary Material section). These parameters were chosen in order to integrate all the scattered intensity of the 
peak. The intensities of 100 lamellar peak, as a function of the angular range $-85^{\circ}<\chi<85^{\circ}$, are shown in figures 3.c and 3.d. This range was selected because of the weak signal for $|\chi|>85^{\circ}$ probably caused by the surface roughness of samples.

As shown schematically in figure 1.b, we can distinguish three orientations: edge-on, face-on, and isotropic. If the scattered intensity arises from the edge-on oriented chains, we can include all chains with an orientation close to $\chi=0^{\circ}$, and the intensity at $\chi=85^{\circ}$ or $-85^{\circ}$ indicates the faceon oriented chains. In isotropic case, the scattering intensity arising from the subset of chains forms a uniform ring with a random distribution ${ }^{[37]}$.

For the film coated on a glass substrate (figure 3.c) most of crystalline polymer chains are edge-on oriented $(\sim 80 \%)$, and the remaining fraction is isotropic. For the layers coated on PDMS (figure 3.d), the crystalline regions are mostly edge-on oriented or isotropic with portions of $\sim 46 \%$ and $\sim 45 \%$ respectively, but there is also a small portion which is face-on oriented. From comparison of these two cases it follows that the films spin-coated on glass are mostly edge-on oriented and more ordered than on PDMS with a FWHM in $\chi 1.4$ times broader. These results mean that the preferential orientation and the ordering of polymer chains are substratedependent. 

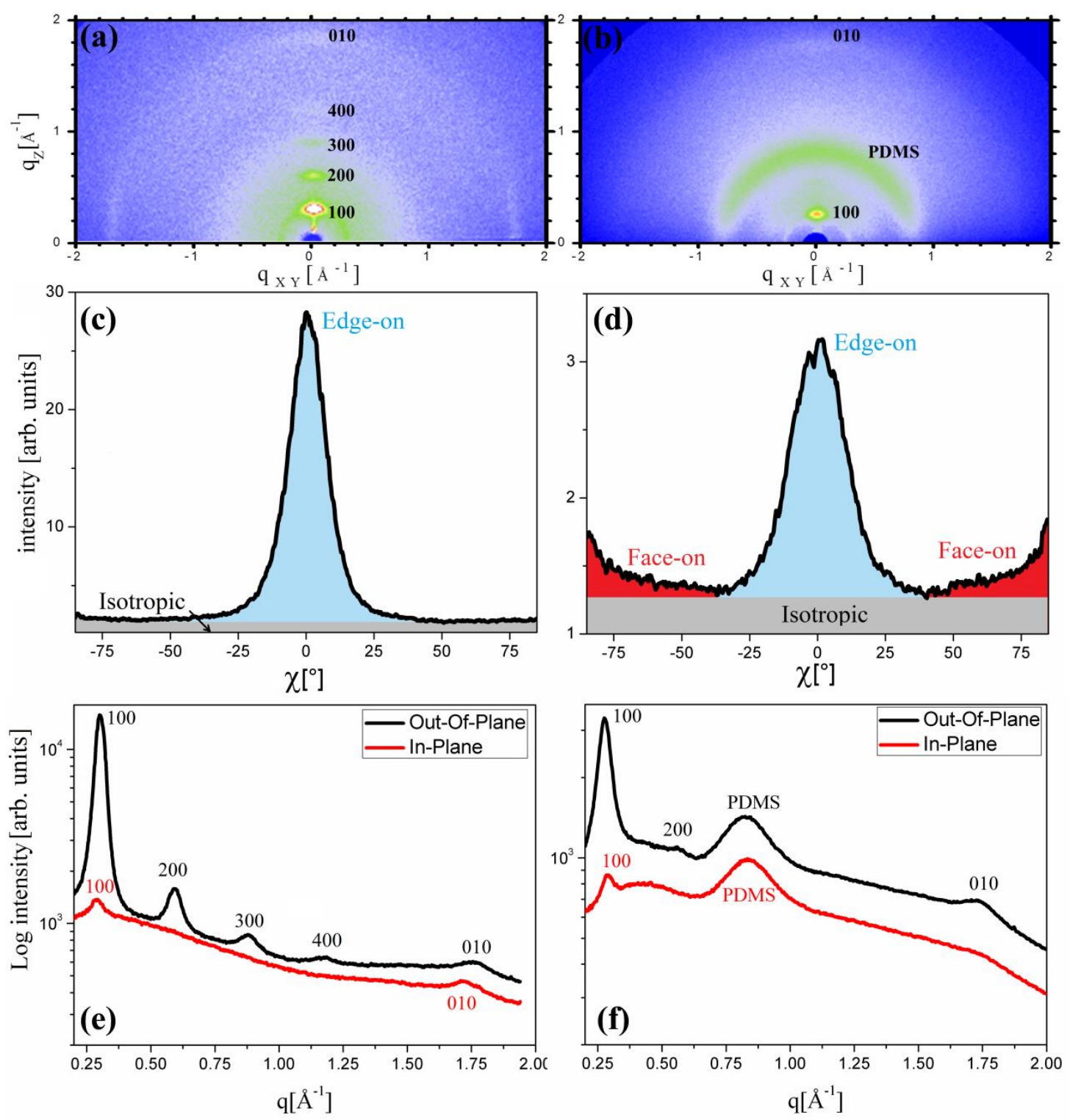

Figure 3. 2D GIXD pattern of PCE11 spin-coated on (a) glass and (b) PDMS. The azimuthal integration along $\chi$ shows the anisotropy of the chain orientation and the portions of face-on or edge-on orientations for the 100 peak of PCE11 spin-coated on (c) glass and (d) PDMS. The corresponding out-of-plane and in-plane integrations show the different peaks of PCE-11 spin coated on (e) glass and (f) PDMS 
Using the integration of pie-cuts along $\mathrm{q}_{\mathrm{z}}$ and $\mathrm{q}_{\mathrm{x}}$ directions (see figure S1.a in Supplementary Material section) we extracted the curves of scattering intensity in the out-of-plane and in-plane directions, as shown in figures 3.e and 3.f for both samples.

Along $\mathrm{q}_{\mathrm{z}}$, we measured the distance between the edge-on oriented polymer chains giving rise to the lamellar peak 100 , and also the aromatic $\pi$ - $\pi$ stacking spacing ( 010 weak peak) of the faceon oriented chains which are perpendicular to the substrate.

Along $\mathrm{q}_{\mathrm{x}}$ we may extract the distance between the face-on oriented polymer chains giving rise to a weak lamellar peak, and the $\pi-\pi$ stacking spacing of the edge-on oriented chains which are parallel to the substrate.

For the 100 lamellar peak along out-of-plane (OOP) $\mathrm{q}_{\mathrm{z}}$ and in-plane (IP) $\mathrm{q}_{\mathrm{x}}$ directions, we extracted the integrated intensity, the peak center and the FWHM of each sample. The results are shown in the table 1.

\begin{tabular}{|c|c|c|c|c|}
\hline \multirow{3}{*}{$\begin{array}{l}100 \text { lamellar peak } \\
\text { Measured integrated }\end{array}$} & \multicolumn{2}{|c|}{ Glass substrate } & \multicolumn{2}{|c|}{ PDMS substrate } \\
\hline & $\operatorname{OOP}\left(q_{z}\right)$ & $I P\left(q_{x}\right)$ & $\mathrm{OOP}\left(q_{z}\right)$ & $I P\left(q_{x}\right)$ \\
\hline & 636 & 16.2 & 17.5 & 7.0 \\
\hline Measured peak position $\left[\AA^{-1}\right]$ & 0.30 & 0.29 & 0.28 & 0.29 \\
\hline Calculated spacing $[\AA ̊]$ & 20.8 & 21.7 & 22.8 & 21.7 \\
\hline Measured FWHM $\left[\AA^{-1}\right]$ & 0.043 & l & 0.057 & 1 \\
\hline $\begin{array}{l}\text { Calculated coherence length } \\
L_{c}[\AA ̊] \text { with Scherrer }\end{array}$ & 131 & 1 & 101 & 1 \\
\hline
\end{tabular}

Table 1. Main structural parameters: peak center, polymer chains spacing $[\AA], \mathrm{FWHM}\left[\AA^{-1}\right]$ and integrated intensity of lamellar peak along $\mathrm{q}_{\mathrm{z}}$ and $\mathrm{q}_{\mathrm{x}}$ directions, of PCE11 spin-coated on glass and PDMS substrates (from figures 3 e and $\mathrm{f}$ ).

As table 1 shows, by comparing the measured integrated intensities along $\mathrm{q}_{\mathrm{z}}$ and $\mathrm{q}_{\mathrm{x}}$ directions, we can see clearly that the layers are strongly edge-on ordered both on glass and PDMS substrate. However, we obtained a ratio of integrated intensities between both directions [ratio = 
Integrated intensity $\left(\mathrm{q}_{\mathrm{z}}\right) /$ Integrated intensity $\left(\mathrm{q}_{\mathrm{x}}\right)$ ] of 40 for PCE11 layer coated on glass and only 18 for PCE11 on PDMS, confirming that the polymer chains of the PCE11 layer coated on the glass substrate show dominating edge-on orientation in comparison to PDMS substrate. Thus, the intensity of 100 peak of PCE11 on glass is around 7 times higher than the one obtained on PDMS, and the FWHM is about $30 \%$ smaller. From the FWHM $\Delta \mathrm{q}$ of each peak, the size of coherent domains can be calculated by Scherrer formula:

$$
L_{C}=2 \pi \frac{0.9}{\Delta q}
$$

Assuming homogeneous distribution of d-spacings, the value obtained on glass is 1.3 times larger than on PDMS. The difference on FWMH could also be attributed to micro-strains (distribution of d-spacings), or disorder that is probably more important on PDMS.

Peak broadening has multiple causes that in common cases can be separated into two main contributions: (i) crystallite size broadening that is independent from the Bragg peak position; (ii) lattice disorder broadening that depends on the Bragg peak position. Both contributions can be well estimated for the PCE11 layer coated on glass substrate, with more than two Bragg reflections to decouple these parameters. Considering the distribution of lattice spacing in $\mathrm{q}$ space as a function of lattice parameter d, one could obtain [38]:

$$
\frac{\Delta q^{2}}{(2 \pi)^{2}}=\left(\frac{0.9}{L_{a}}\right)^{2}+\frac{(\pi g)^{4}}{d^{2}} n^{4}
$$

with $L_{a}$ the crystallite size and $g$ the paracrystalline disorder parameter.

We plotted $\Delta q^{2}$ as a function of $n^{4}$, for 3 orders $\mathrm{n}$ of h00 Bragg peak, and obtained a g-factor equals to $4.5 \%$, with a crystallite size of $119 \AA$.

Thus, introducing this disorder parameter is more realistic, and the calculated size of coherent domains $\mathrm{L}_{\mathrm{c}}$ is even smaller than without this g parameter. 


\begin{tabular}{|c|c|c|}
\hline 100 lamellar peak & $\begin{array}{l}\text { Glass } \\
\text { substrate }\end{array}$ & $\begin{array}{l}\text { PDMS } \\
\text { substrate }\end{array}$ \\
\hline $\begin{array}{l}\text { Measured FWHM }\left[\AA^{-1}\right] \\
1^{\text {st }} \text { order Bragg peak }\end{array}$ & 0.043 & 0.057 \\
\hline $\begin{array}{l}\text { Calculated crystallite size } L_{c}[\AA] \\
\text { with Scherrer }\end{array}$ & 131 & 101 \\
\hline Calculated disorder parameter $\mathbf{g}(\%)$ & 4.5 & - \\
\hline $\begin{array}{l}\text { Calculated crystallite size } L_{a}[\AA] \\
\text { assuming disorder parameter }\end{array}$ & 119 & - \\
\hline $\begin{array}{l}\text { Estimated disorder parameter } \mathbf{g}(\%) \\
\text { with fixed crystallite size } L_{a}\end{array}$ & - & 10.7 \\
\hline $\begin{array}{l}\text { Estimated crystallite size } L_{a}[\AA] \\
\text { with fixed disorder parameter } g\end{array}$ & - & 99 \\
\hline
\end{tabular}

Table 2. Comparison of crystallite size and disorder parameter of PCE11 layers coated on glass and on PDMS substrate.

The extraction of physical parameters from the Bragg peak width is more difficult for PCE11 coated on PDMS, since only one diffraction order is really usable, which does not allow such a decoupling to be done. In this case, two boundary assumptions can be done:

(1) disorder is supposed to be the same as for the films deposited on glass ( $\mathrm{g}=4.5 \%$ like on glass substrate); we obtain an estimated size of crystalline domains $\mathrm{L}_{\mathrm{a}}=99 \AA$.

(2) coherent domain size is supposed to be the same as on glass substrate $\left(\mathrm{L}_{\mathrm{a}}=119 \AA\right)$, which gives an estimated value of disorder $\mathrm{g}=10.7 \%$.

In any case, these differences between the two substrates mean that the layers coated on glass are more ordered and better crystallized than on PDMS.

\subsection{Structural properties evolution under mechanical load}

In-situ GIXD measurements were performed under uniaxial tensile test, to probe the impact of stress on the molecular ordering of the polymer chains and their deformation. We plotted the intensity evolution of the out-of-plane lamellar 100 peak versus the scattering vector $\mathrm{q}_{\mathrm{z}}\left(\AA^{-1}\right)$, for different values of stretching (the stretch is calculated via the relative distance between the 
tensile device jaws). These curves are extracted from the pie-cut integration of recorded 2D images as explained in section 3.1.

From the curves of figure 4, we can see two different trends. First (figure 4.a), from $0 \%$ to $15 \%$ of stretching a shift of the peak position to higher $\mathrm{q}_{\mathrm{z}}$ values is evidenced, which means that the vertical spacing between polymer chains decreases under stretching. Secondly (figure 4.b), after reaching a critical value between $15 \%$ and $20 \%$ of stretching, an opposite shift of the peak position to smaller values of $\mathrm{q}_{\mathrm{z}}$ is observed, corresponding to an increasing spacing.
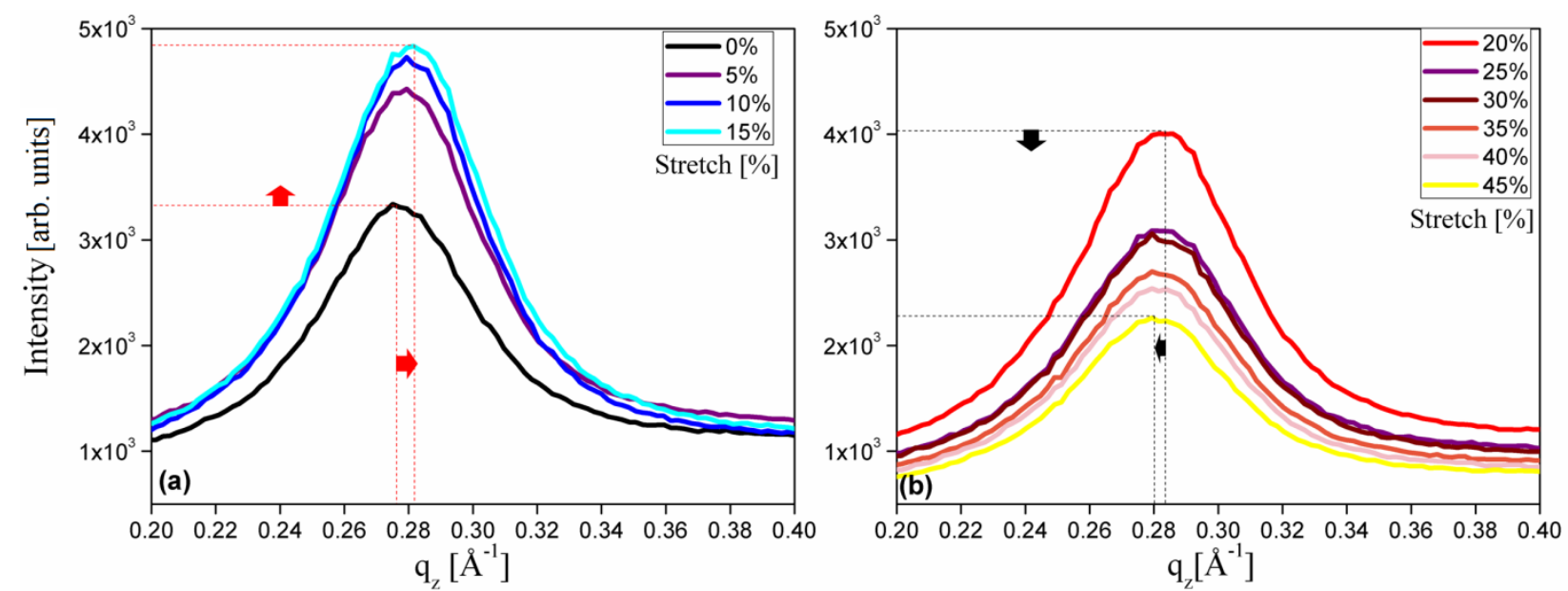

Figure 4. The out-of-plane integration showing the evolution of the 100 lamellar peak (a) under [0\%:15\%] of stretching; and (b) under [20\%:45\%] of stretching

Figure 5.a shows the changes in integrated intensity $\Delta \mathrm{I}$ as a function of applied stretch for the out-of-plane 100 peak.

$$
\Delta \mathrm{I}(\%)=100\left(\mathrm{i}-\mathrm{i}_{0}\right) / \mathrm{i}_{0}
$$

Until $15 \%$ of stretching a remarkable increase of the integrated intensity by $76 \%$ is evidenced, meaning that the amount of edge-on ordered polymer chains increases until this value of stretching. We calculated the evolution of edge-on area ratio during stretching and we obtained an increase of $65 \%$ (at $15 \%$ stretch). For larger deformations, the integrated intensity decreases 
steadily reaching a value similar to the initial state at $30 \%$ of stretching, and going to lower values for even larger deformations, which corresponds to a decrease of edge-on oriented chains in the crystalline regions.
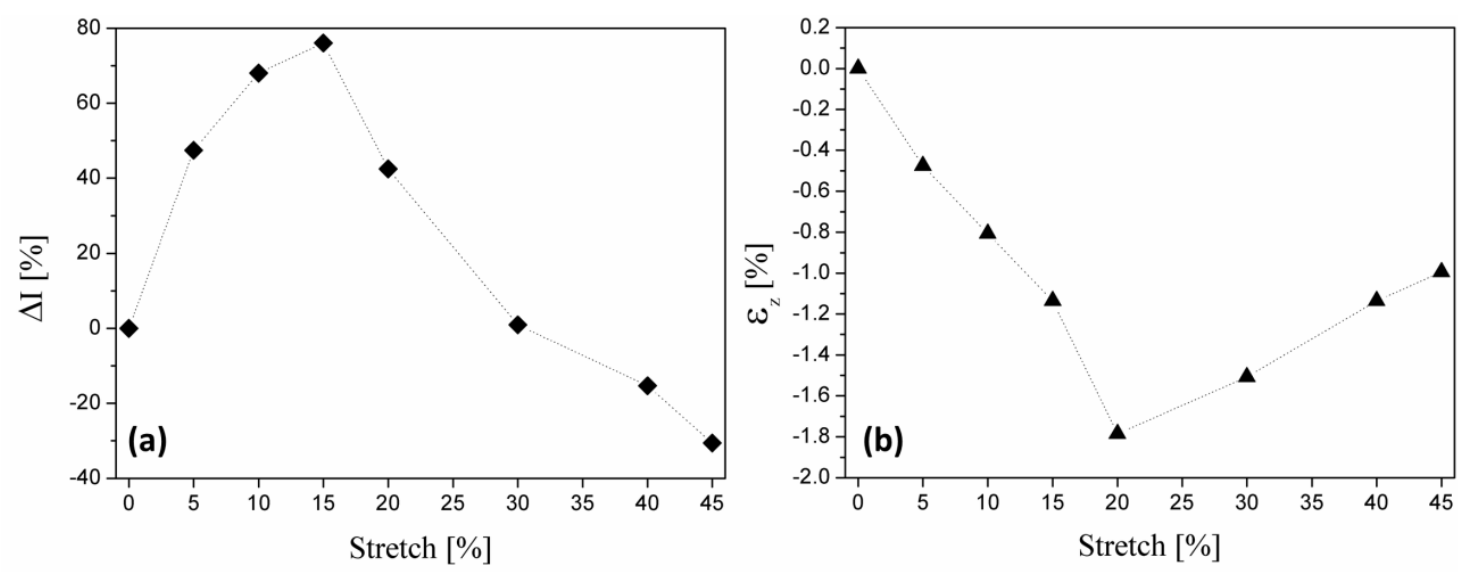

Figure 5. (a) The change in normalized integrated intensity of the 100 lamellar peak versus stretching. (b) The strain evolution of the 100 lamellar spacing under stretching

In order to better quantify the mechanical behavior of the layers, we calculated the strain $(\varepsilon)$ of polymer chains along $\mathrm{q}_{\mathrm{z}}$, which is defined as the change of the spacing between polymer chains $\left(d-d_{0}\right)$ divided by the initial spacing $\left(d_{0}\right)$ :

$$
\varepsilon_{\mathrm{z}}=100\left(\mathrm{~d}-\mathrm{d}_{0}\right) / \mathrm{d}_{0}
$$

Figure 5.b shows the strain evolution of polymer chains along $\mathrm{q}_{\mathrm{z}}$. The negative values of $\varepsilon_{z}$ can be interpreted as a Poisson compressive strain resulting from the applied stress along the $\mathrm{Y}$ stretching direction. Assuming perfect adhesion the strain of the film along $\mathrm{Z}$ should be:

$$
\varepsilon_{33 f}=-v_{f} \frac{1-v_{s}}{1-v_{f}} \varepsilon_{11 S}
$$

Where $v_{s}$ and $v_{f}$ are respectively the Poisson ratios of substrate and film and $\varepsilon_{11 s}$ is the applied strain on the substrate. Poisson Ratio of PDMS is $0.5^{[21]}$ and we assume a Poisson ratio of 0.35 for PCE11 (like that of P3HT ${ }^{[37]}$ ). 
The strain along $\mathrm{Z}$ should be $-5.4 \%$ at $20 \%$ of stretching. However, for the 100 lamellar peak, until $20 \%$ of stretching the deformation value for PCE 11 goes down from $0 \%$ to $-1.78 \%$, roughly linearly. Above $20 \%$ stretching we observe stress relaxation (back to $-0.99 \%$ of deformation when the substrate is broken). Since the maximum observed strain is $-1.8 \%$ instead of the predicted $-5.4 \%$ one has to assume a reduced load transfer from substrate to the crystalline regions of the polymer; this could be explained by the fact that the applied strain is mostly distributed in the amorphous regions of the polymer. For the aromatic $\pi-\pi$ stacking peak (not shown here) along the vertical direction, the polymer chains are also under negative strain, but after $20 \%$ of stretching it becomes more difficult to determine the strain evolution because the diffraction peak is very weak. Comparing the strain of the polymer chains between these two orientations, we measured $-1.78 \%$ and $-0.4 \%$ of strain for the lamella (edge-on) and the $\pi$ $\pi$ stacking (face-on), respectively, under $20 \%$ of stretching, which shows the anisotropic character of elasticity in the polymer. This may explain the anisotropic properties of the layer and the good photovoltaic and electrical properties of these polymers under mechanical load as well. ${ }^{[21]}$ Furthermore, charge transport is highly anisotropic in $\pi$-conjugated systems, being most effective along the aromatic $\pi-\pi$ stacking direction giving rise to 010 peak and poor along the insulating alkyl side chains between the lamellar distances giving rise to 100 lamellar peak. ${ }^{39}$, $40,41]$

\subsection{In-situ optical Microscope Observations of the surface}

To follow the microstructure and get insights into the origin of the relaxation mechanism that works above $20 \%$ stretching we also performed in situ microscopic observations of the PCE11 surface under stretching. The images under stretching are shown in figure $\mathbf{6}$ and demonstrate 
cracking of the polymer surface. The crack-onset strain is of the order of $10 \%$, and cracking dominates the mechanical behavior beyond $18 \%-20 \%$. Bao et al also observed the first cracking of layers between $8 \%$ and $12 \%$ and the cracks spreading at $20 \%$ of stretching. ${ }^{[6]}$

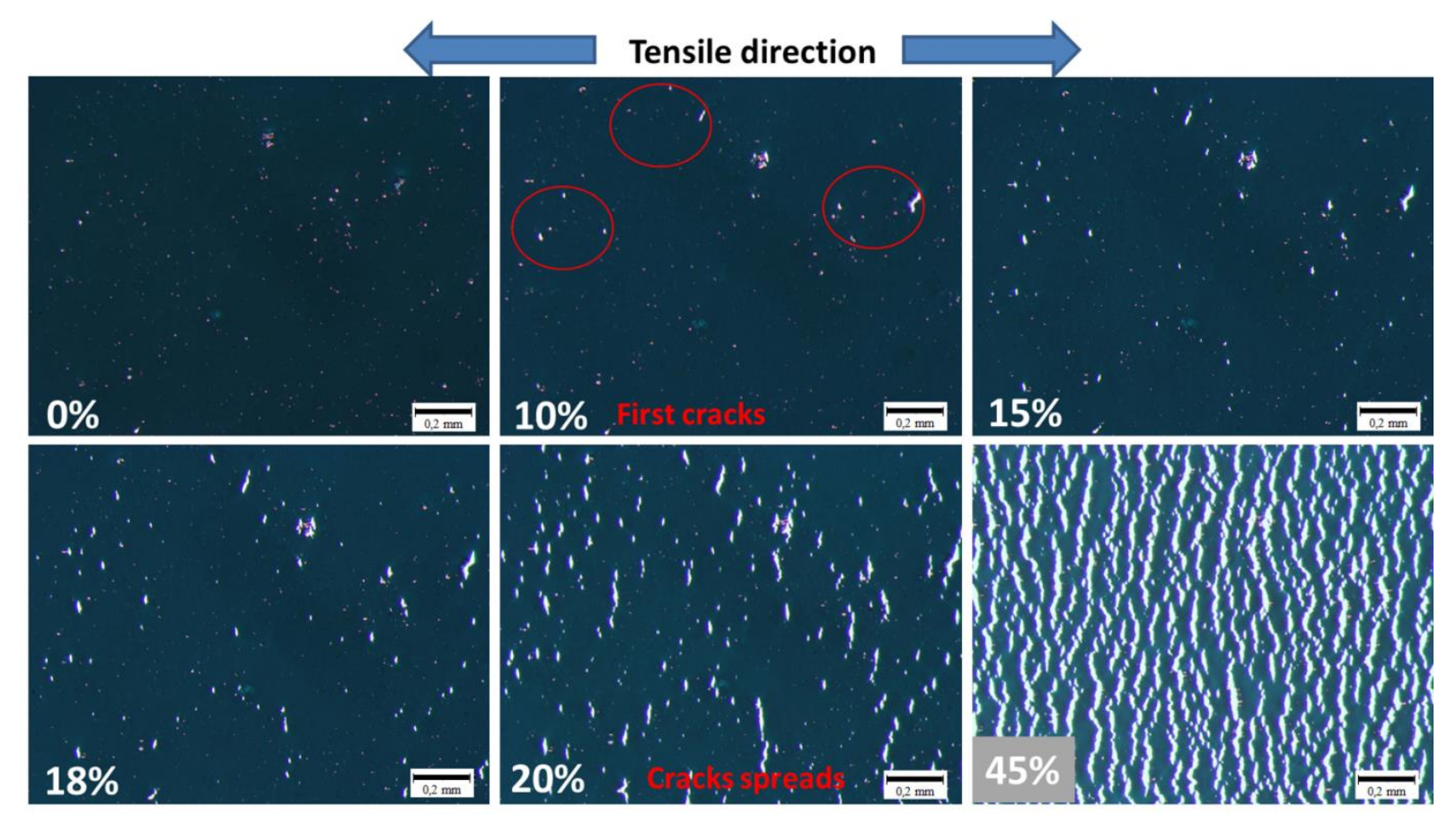

Figure 6. Optical microscope images of the surface of PCE11 layer under stretching

For a better quantification of these images, statistics on the cracks were performed to extract their dimensions (width and length) and their number. For that purpose, we considered elliptic shapes, and we took into account only defects bigger than $100 \mu \mathrm{m}^{2}$, on a surface unit of $1 \mathrm{~cm}^{2}$. For the crack dimensions estimation, the average value of length and width was taken into account, with a standard deviation about $20 \mu \mathrm{m}$ because the crack's sizes are not homogeneous. The total area was calculated by taking the sum of all cracks areas. The in-situ evolution of the number and dimensions of cracks, and their normalized total area are shown in figure 7.

As shown in figure 7.a, the number of cracks increases dramatically in the range from $15 \%$ to $25 \%$ of stretching ( 15 times at $20 \%$ ). The length of cracks increases faster than the width and the 
propagation of cracks is almost perpendicular to the stretching direction. The decrease in the number of cracks between $40 \%$ and $45 \%$ of stretching is explained by the fact that the cracks coalesce. Besides, the total area is always increasing under stretching (figure 7.b).
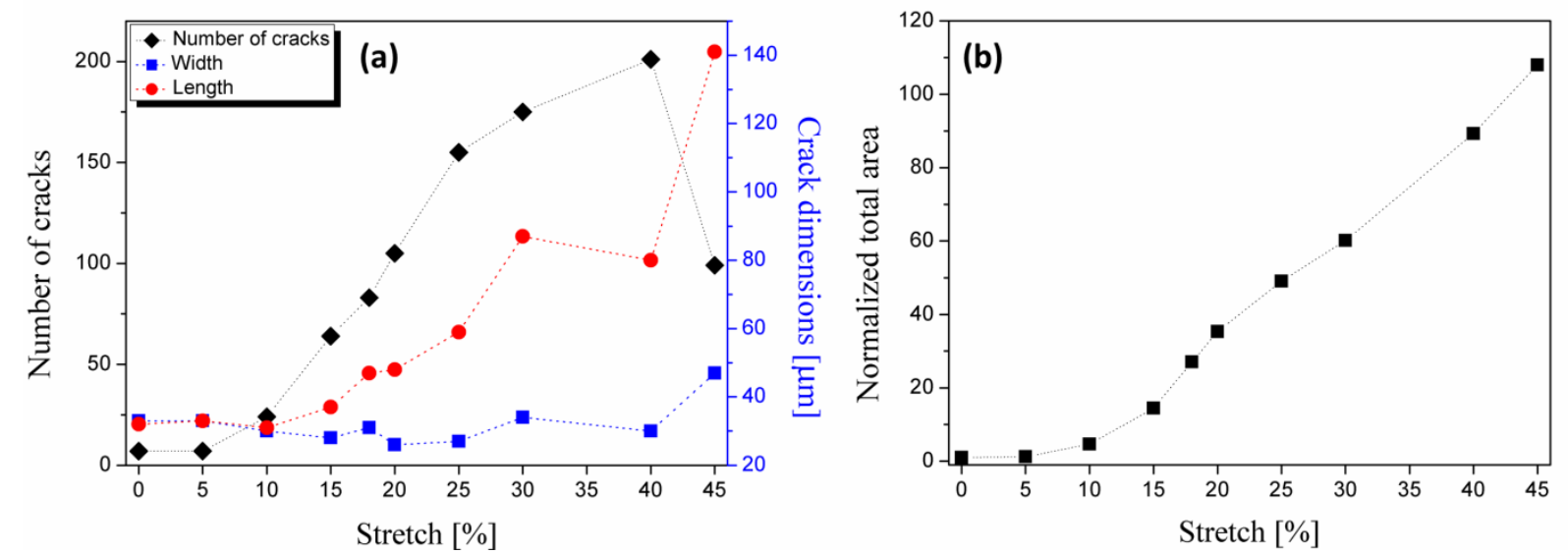

Figure 7. The evolution of (a) the average width, the average length and the number of cracks; (b) the normalized total area of cracks, under stretching

Overall, the in situ optical microscope observations are in good correlation with the GIXD measurements. These observations show that after a critical value of $10-15 \%$ of stretching cracking occurs in the polymer layer. At the same time the average elastic strain measured by GIXD decreases as a consequence of stress relaxation along the crack boundaries. The elastic strain energy stored in the PCE11 films decreases as a result of increasing crack length developed upon stretching higher than $20 \%$.

Moreover, recycle experiments have been performed on blend polymer films (in the range $0-10 \%$ of stretch), and in this range we could observe a reversible behavior. We may assume from cycling experiments that there is a reversible regime at least up to $10 \%$ stretch.

\section{Conclusion}


We studied the structure of PCE11 $\pi$-conjugated polymer layer under mechanical load on stretchable support by using in situ GIXD measurements coupled with optical observations. This study reveals that spin-coated layers of this polymer are mostly edge-on oriented. Tensile tests show that in the out-of-plane direction the polymer chains which are perpendicular to the stretching direction undergo increasing compressive strain until $15 \%-20 \%$ stretching in agreement with a Poisson effect. Further on, beyond $20 \%$ a partial strain relaxation takes place. Optical observations indicate that massive crack propagation occurs at $20 \%$ of stretching, which explains the strain relaxation. Comparing the imposed displacement with the measured strain a weak load transfer from the substrate to the crystalline part of the polymer is inferred, which leads to the conclusion that the applied tension may be distributed in the amorphous regions of the polymer which plays a role of a force damper. The polymer chains are less sensitive to the applied tension along the aromatic $\pi-\pi$ stacking order. This behavior has to be confirmed on blends and is correlated with the good photovoltaic properties of layers before cracking spreads at $20 \%$ stretching [22]. Beyond the results specific to PCE11 films, the presented in situ method can be applied to any partially crystallized polymer films for stretchable electronics. This setup allows for a very detailed in-situ investigation of structure under stretching in these polymer films or blends.

\section{Acknowledgements}

This work was supported by DAAD-PROCOPE (Project No. 57211900) and PHC-Tassili (Project No. 17MDU4994). We are grateful to S. Laifa for assistance in PDMS supports elaboration, L. Grodd, K. Shchyrba and the mechanical workshop at the University of Siegen for 
assistance in the construction of the stretching device, and C. Sternemann, M. Paulus for support during the experiment at BL9 beamline at the DELTA synchrotron (Dortmund, Germany). 


\section{Supplementary material}

In order to quantify the orientation of polymer chains and their anisotropy, an integration of the scattered intensity from the 2D GIXD patterns of PCE11 is necessary.

For that purpose, we performed an azimuthal integration of the patterns by an arc-cut, as represented in figure S1.a. This arc is characterized by its radius $\left(r=0.29 \AA^{-1}\right)$, width $(w=0.1$ $\left.\AA^{-1}\right)$, center (obtained by calibration using Silicon powder), and its angular range $(\chi \in$ $\left.\left[-85^{\circ} ; 85^{\circ}\right]\right)$. The azimuthal integration along $\chi$ angle provides information on the portions of face-on or edge-on orientations, here for the 100 peak of PCE11 layer.

In order to get the different peaks of PCE-11 either along in-plane or along out-of-plane directions, we used an integration of pie-cuts along $\mathrm{q}_{\mathrm{zy}}$ or $\mathrm{q}_{\mathrm{z}}$ directions respectively, as shown in in figure S1.b, with a solid angle of $20^{\circ}$. The corresponding integrations show the predominant orientation of polymer chains along each direction. 


\section{References}

[1] A. Sugimoto, H. Ochi, S. Fujimura, A. Yoshida, T. Miyadera, M.Tsuchida. IEEE Journal of selected topics in quantum electronics. 2004,10,1.

[2] M-C. Choia, Y.Kimb, C-S. Haa, Prog. Polym. Sci. 33. 2008, 581-630.

[3] T. Sun, J.I. Scott, M.Wang, R.J. Kline, G. C. Bazan, B.T. O’Connor. Adv. Electron. Mater. 2017, 3, 1600388.

[4] B. H. Lee, B. B.Y. Hsu, S. N. Patel, J. Labram, C. Luo, G. C. Bazan, A. J. Heeger. Nano Lett. 2016, 16, 314-319.

[5] Z. Liu, J.Li, Feng Yan. Adv. Mater. 2013, 25, 4296-4301.

[6] D.J. Lipomi, B.C.-K. Tee, M. Vosgueritchian, Z. Bao, Adv. Mater. 2011, 23, 1771-1775.

[7] S.J. Benight, C. Wang, J. B. H. Tok, Z. Bao, Progress in Polymer Science. 2013, 38 ,19611977.

[8] B. C. Thompson, J. M. J. Fréchet, Angew Chem Int Ed. 2008, 47 , 58.

[9] A.Facchett, Chem. Mater. 2011, 23, 733-758 733.

[10] N. Karl, Synth Met. 2003, 133 134, 649.

[11] H. Sirringhaus, Nat. Mater. 2003, 2, 641.

[12] A. Pron, R. Progr. P. Polym. Sci. 2002, 27, 135.

[13] F. C. Philos, Trans. R, Soc. London, Ser. A. 2000, 358, 173.

[14] H. E. Katz, Chem. Mater. 2004, 16, 4748.

[15] S. Allard, M. Forster, B. Souharce, H. Thiem, U. Scherf, Angew Chem Int Ed. 2008, 47, 4070.

[16] M. C. LeMieux, Z. Bao, Nat. Nanotechnol. 2008 , 3 , 585 .

[17] J. A. Rogers, T. Someya, Y. G. Huang, Science. 2010 327, 1603.

[18] T. Someya, Nat. Mater. 2010, 9, 879 .

[19] R. H. Kim , D. H. Kim , J. L. Xiao , B. H. Kim , S. I. Park , B. Panilaitis ,R. Ghaffari, J. M. Yao , M. Li , Z. J. Liu , V. Malyarchuk, D. G. Kim, A. P. Le, R. G. Nuzzo , D. L. Kaplan, F. G. Omenetto , Y. G. Huang , Z. Kang, J. A. Rogers , Nat. Mater. 2010, 9 , 929.

[20] F. C. Krebs, T. D. Nielsen, J. Fyenbo , M. Wadstrom , M. S. Pedersen, Energy Environ. Sci. 2010, 3 , 512. 
[21] D. J. Lipomi, H. Chong, M. Vosgueritchian, J. Mei, Z. Bao, Solar Energy Materials \& Solar Cells. 2012, 107,355-365.

[22] C. Lu, W-Y. Lee, X. Gu, J. Xu, H-H. Chou, H. Yan, Y-C. Chiu, M. He, J. R Matthews, W. Niu, J. B-H. Tok, M. F. Toney, W-C. Chen, Z. Bao. Adv. Electron. Mater. 2017, 3, 1600311.

[23] B. O’Connor, R. J. Kline , B. R. Conrad, L. J. Richter, D. Gundlach, M. F. Toney, D. M. DeLongchamp . Adv. Funct. Mater. 2011, 21, 3697-3705.

[24] L. Grodd, U.Pietsch, S. Grigorian, Macromol. Rapid Commun. 2012, 33, 1765-1769.

[25] E. Mikayelyan, A. V. Bakirov, M. A. Shcherbina, S. N. Chvalun, S. A. Ponomarenko, S. Grigorian, RSC Advances 2015, 5, 1319-1322.

[26] S. Grigorian, S. Escoubas, D. Ksenzov, D. Duche, M. Aliouat, J.-J. Simon, B. Bat-Erdene, S. Allard, U. Scherf, U. Pietsch, and O. Thomas. J. Phys. Chem. C , 2017, 121 (41), 2314923157.

[27] J. Zhao, S. Zhao, Z. Xu, B. Qiao, D. Huang, L. Zhao, Y. Li, Y. Zhu, P. Wang, ACS Appl. Mater. Interfaces. 2016, 8, 18231-18237.

[28] Q. Sun, F. Zhang, Q. An, M. Zhang, J. Wang, J. Zhang, Phys.Chem.Chem.Phys. 2017,19, 709.

[29] H. W.Ro, J. M. Downing, S. Engmann, A. A. Herzing, D. M. DeLongchamp, L. J. Richter, S. Mukherjee, H. Ade, M. Abdelsamie, L. K. Jagadamma, A. Amassian, Y. Liu, H. Yan, Energy Environ. Sci. 2016, 9, 2835.

[30] R. Noriega, J. Rivnay, K. Vandewal, F.P.V. Koch, N. Stingelin, P. Smith, M.F Toney, A. Salleo, Nat Mater, 2013, 12, 1038-1044.

[31] T. Heumueller, W. R. Mateker, A. Distler, U. F. Fritze, R. Cheacharoen,W. H. Nguyen, M. Biele, M. Salvador, M.Delius, H-J. Egelhaa, M.D. McGehee, C.J. Brabec, Energy Environ. Sci. 2016, 9, 247-256.

[32] S. Joshi, P. Pingel, S. Grigorian, T. Panzner, U. Pietsch, D. Neher, M. Forster, U. Scherf, Macromolecules 2009, 42, 4651.

[33] G. Li, R. Zhu, Y. Yang, Polymer solar cells, Nature Photonics. 2012, 6,153-161.

[34] M. Jorgensen, K. Norrman , F. C. Krebs , Sol. Energy Mater. Sol. Cells 2008, 92 , 686.

[35] K. Efimenko, W. E. Wallace, J. Genzer, Journal of Colloid and Interface Science .2002,254, $306-315$. 
[36] C. M. Stafford , C. Harrison, K. L. Beers , A. Karim , E. J. Amis , M. R. Vanlandingham , H. C. Kim , W. Volksen , R. D. Miller, E. E. Simonyi , Nat. Mater. 2004, 3 , 545.

[37] S.E. Root, S. Savagatrup, C.J. Pais, G. Arya, and D. J.Lipomi, Macromolecules 2016, 49, 7, 2886-2894

[38] T. G. Dane, J.E. Bartenstein, B. Sironi, B.M. Mills, O.A. Bell, J. E. Macdonald, T. Arnold, C.F. J. Faul, W.H. Briscoe, Phys. Chem. Chem. Phys. 2016, 18, 24498-24505. supplementary

[39] A. Hamidi-Sakr , L. Biniek , S. Fall , M. Brinkmann , Adv. Funct. Mater. 2016, 26, 408420.

[40] E. J. W. Crossland, K. Tremel, F. Fischer, K. Rahimi, G. Reiter ,U. Steiner, S. Ludwigs , Adv. Mater. 2012, 24,839 .

[41] L. H. Jimison, M. F. Toney , I. McCulloch , M. Heeney , A. Salleo , Adv.Mater. 2009 , 21 , 1568 .

\section{AUTHOR INFORMATION:}

Corresponding Authors:

Stéphanie Escoubas : stephanie.escoubas@univ-amu.fr

Souren Grigorian : grigorian@physik.uni-siegen.de 


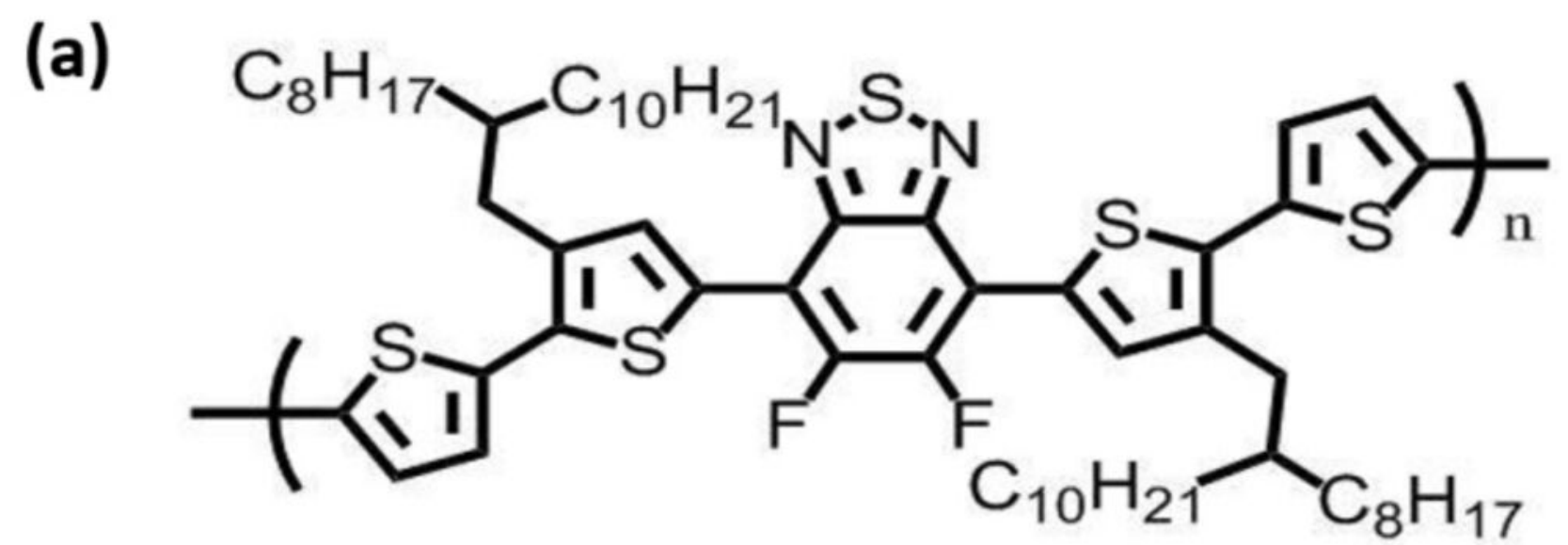

(b)

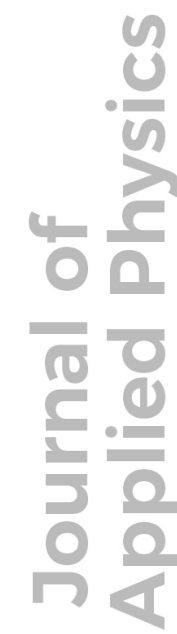

Isotropic orientation of chains
Face-on oriented chains

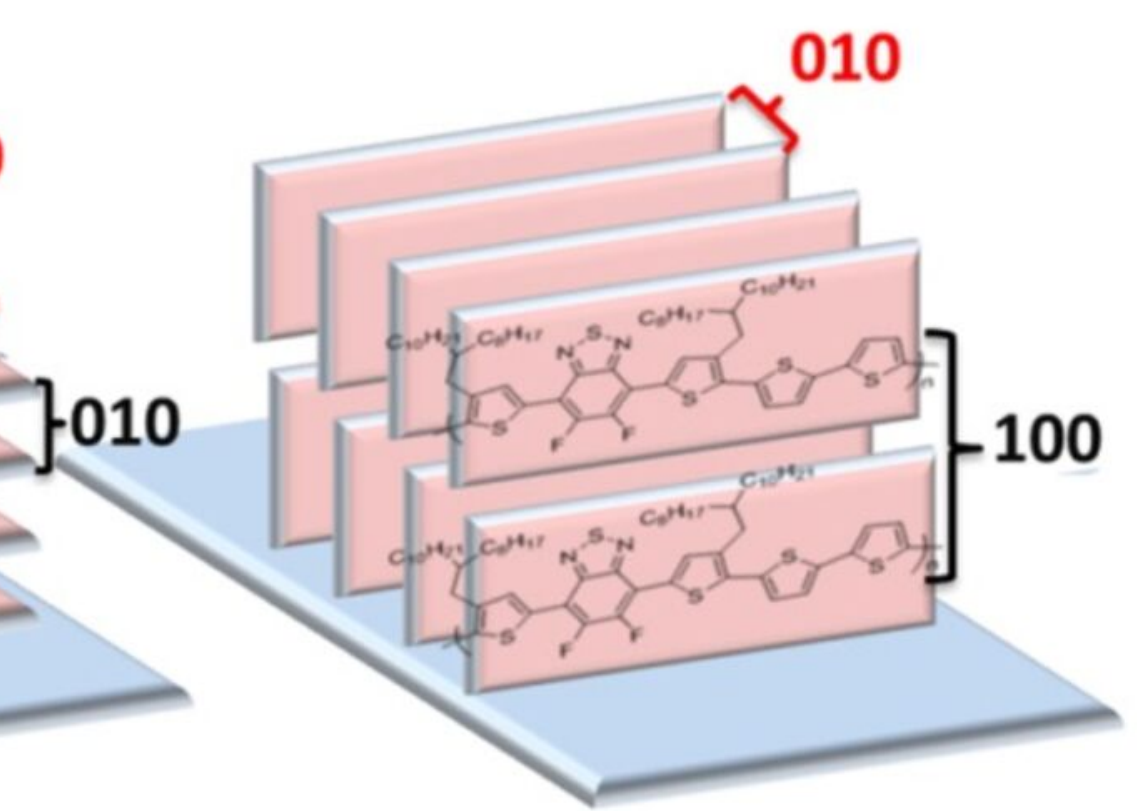

Edge-on oriented chains 

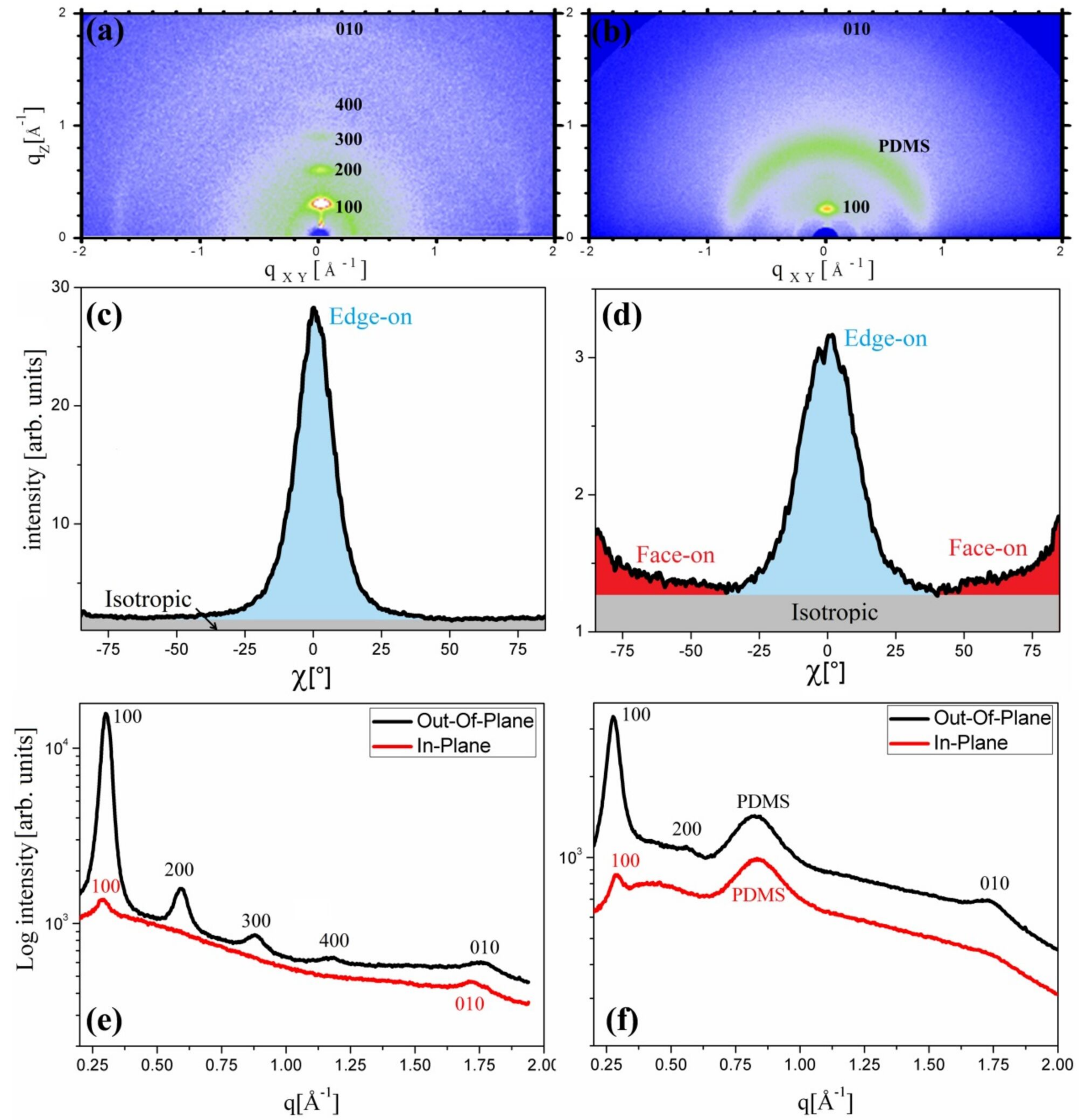

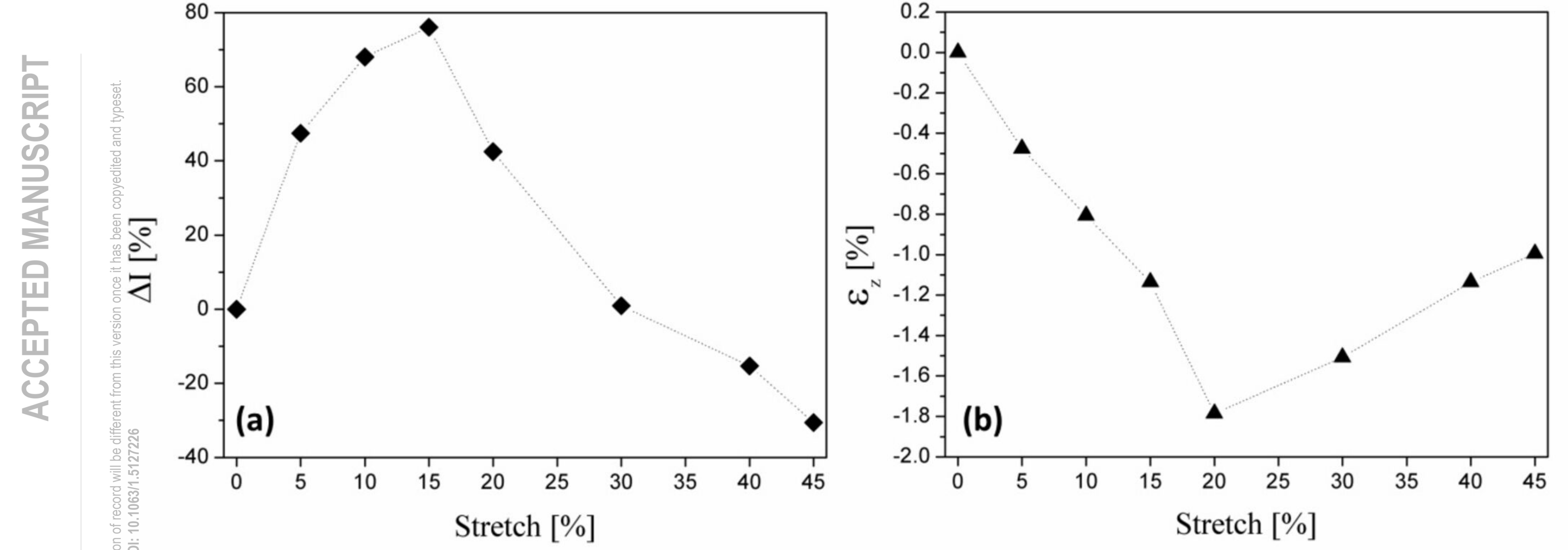
Tensile direction

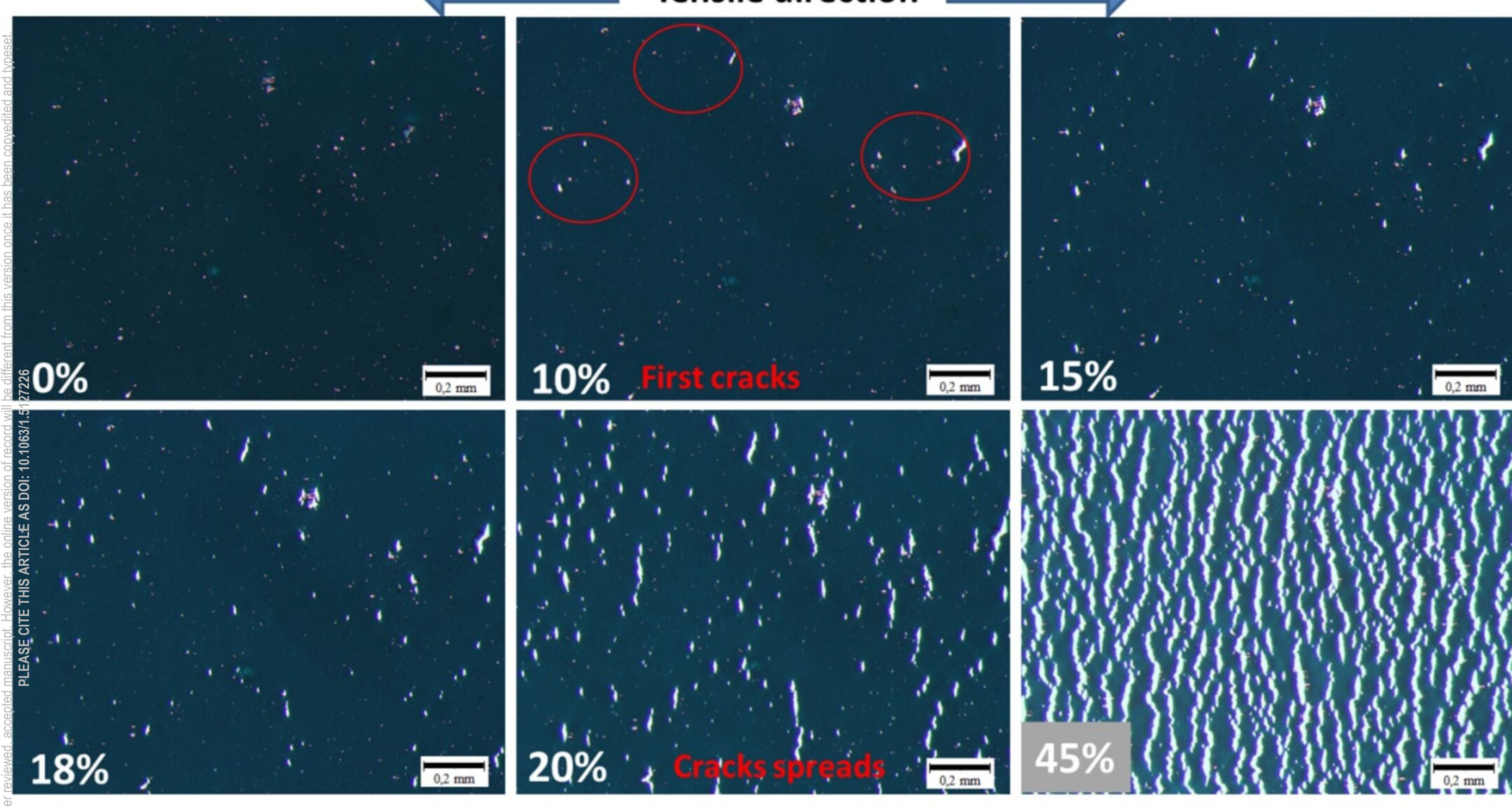



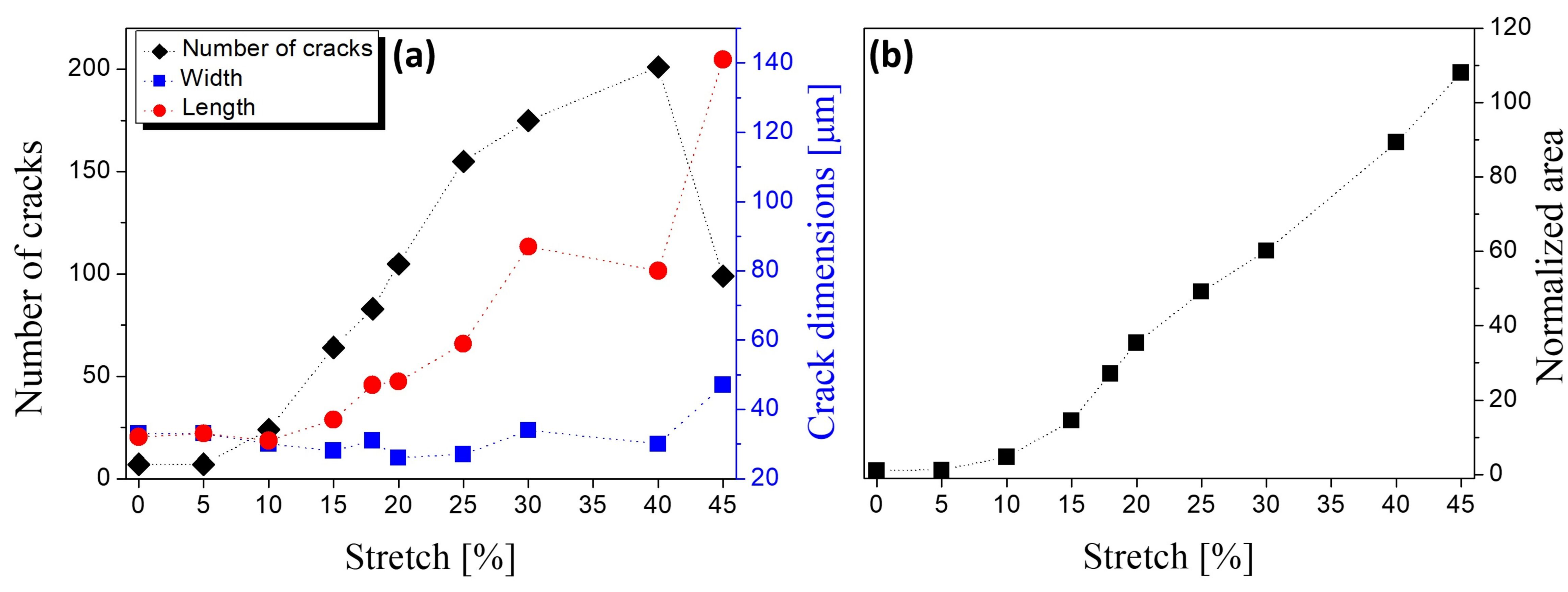